\title{
Basic principles of partnership as the factor of sustainable development in the context of business ecosystems
}

\author{
Natalya Ivashchenko ${ }^{1, *}$, and Ludmila Isaeva $^{2}$ \\ ${ }^{1}$ Russian state University after A.N. Kosygin (Technologies. Design. Art), Sadovnicheskaya Str., 33, \\ building 1, 115035 Moscow, Russia \\ ${ }^{2}$ Limited liability company "SOYUZ ARBAT", Presnenskaya emb., 12, 123317 Moscow, Russia
}

\begin{abstract}
It is the ability to adapt to external conditions, correctly build internal and external relations that today is able to bring a business to a higher level of effective and sustainable development. This is the main rationale for building partnerships that mobilize internal resources and create new opportunities for the benefit of all stakeholders. The transformation of business into an ecosystem, the use of the principles inherent in natural ecosystems is the best response to the challenges of modern socio-economic reality. The peculiarity of this stage of business development lies in the management of the organization as an element of the business ecosystem. The activities of business ecosystems are built on the basis of partnerships, which in this context have a number of features. The article examines the main types and aspects of business ecosystems, traces the stages of their formation, systematizes and reveals the features and basic principles of partnerships, based on which, within such systems, organizations may ensure their effective and sustainable development.
\end{abstract}

\section{Introduction}

Since the end of the 19th century, the problems of sustainable development have always been in the field of attention of economists, managers, scientists and practitioners, "green" organizations, in the political sphere, etc. This is due to the irreparable waste of some natural resources and to the ever-increasing pollution of the environment, which, in turn, jeopardizes the possibility of life and meeting the needs of future generations.

It must be said that the issues of terminology and definition of sustainable development means, assessment of their level and significance continue to be actively discussed. Some points of view on this matter are considered in sufficient detail by the author in the work "Conceptual analysis of the concept of" sustainable business development" [1]. Without repeating the material presented earlier, let us dwell only on the conclusions made earlier concerning the definition of the problem of sustainable development.

The post-industrial era, which is characterized by high rates of increase in knowledge, an information boom and the associated constant disturbances in the internal and external

\footnotetext{
* Corresponding author: suncycle@mail.ru
} 
environment of organizations, provoked an increase in activity in the scientific and business environment to study sustainable development issues.

The concepts of sustainable development are distinguished in relation to the objects of change (development of the country and territory, business and organization) and to the subject of changes (production, financial, marketing, scientific and technical development, etc.). Ambiguous, although very close concepts are the concepts of "sustainable business development" and "sustainable development of the organization." Business development - on the one hand, motivates the development of an organization as its superstructure, on the other hand, the development of an organization, its production and management subsystems, in turn, leads to business development.

The concept of sustainable business development is defined by the authors in the following aspects:

- the desire to ensure the balance of the internal structure and dynamics of the organization's development in each separate period of time, despite the ongoing internal and external changes [2];

- transition from a less efficient state to a more efficient one [3];

- creating long-term value for a wide group of stakeholders, including future generations among others [4].

Linking sustainable development with the need to comply with the interests of all stakeholders of the company, the authors thereby emphasize the importance of achieving mutually beneficial partnership in the long term as one of the most important factors in the sustainable development of companies.

The need to form an effective partnership today is a paradigm for business development, whether it is about external or internal, social or business partnerships, strategic partnerships of organizations or public-private partnerships. In an era of turbulent transformation, coordinated interaction with partners to achieve individual and joint results is one of the building blocks for maintaining the competitiveness of the enterprise. The emergence of new forms of cooperation and business models requires their close study in order to be able to use them to increase the sustainability of development [1]. This new form of cooperation in many sectors of the economy is the transition from a traditional business model to a business ecosystem.

The most actively developing sectors of the economy in Russia in this area should be recognized as the market for Internet sales, IT-technologies and retail banking services. For example, yesterday's Sberbank, and now just Sberbank, today practically makes a transition "from the model of a classical provider of financial services ... to a model of a global ecosystem" [5], applying new financial digital solutions and technologies. Today, in the personal account of a bank client, one may open an account, request a card issue, take out insurance, pay bills and taxes, set a budget, analyze expenses, make an appointment and get a consultation with a doctor, reserve a table in a restaurant, make a reservation and pay a bill, order food for house, etc. It develops its ecosystem and its partnerships in the B2C market and Mail.ru Group, creating more and more new services to meet the online needs of its users. Today the company is already entrenched in classifications, food tech, mobility and commodity e-commerce, education, e-sports and travel.

In this regard, in this work, the task is to characterize, on the basis of generalization and development of the research results of various authors, the modern features of partnership in the context of business ecosystems, which are today the most promising form of transformation of business models of organizations, to determine the differences between partnership in traditional business models and in business -ecosystems. 


\section{Analysis of the concept, stages of development of the theory and types of ecosystems as a form of organizational partnership}

Modern socio-economic reality is characterized by the globalization of the economy, variability, unpredictability and heterogeneity, the complication of production processes and products that are becoming high-tech both in the field of production, logistics, and in the sphere of consumption. Following this, management and business models are being rebuilt. Increasing complexity in production and management requires a higher level of competence and adaptability. An increasing role in production and consumption is played by the use and transmission of information (big data, cloud technologies, artificial intelligence, etc.), which is associated with the widespread transition to the digital economy.

The boundaries of organizations are blurred, which becomes possible as a result of the development of information technologies, virtual organizations and inter-organizational teams appear, new forms of doing business and new forms of partnership are formed, since today it is often is not enough.

All this raises the need for large-scale and multifaceted, external and internal partnerships within the value chain, and this partnership may go beyond one country. Forms and subjects of partnership are significantly expanding; in addition to suppliers, intermediaries and consumers, partnerships involve not only government, educational institutions, various public funds, but also competitors, employees of the lower levels of the organization. This form of partnership is formed if we consider a business company as an ecosystem that exists and develops pursuant to the laws of the evolution of wildlife.

The emergence of the theory of business ecosystems is associated with the research of Marshall (1890) in the field of spatial agglomeration of industrial enterprises in Victorian England and the subsequent statements of Jacobs (1969) about the spread of knowledge between unrelated industries within urbanized agglomerations.

Discussions on the industrial ecosystems began in the 1990s, when the need to implement the principles of sustainable development appeared in the center of consideration. This meant doing business in an environmentally friendly way, using each other's energy and waste. An industrial ecosystem was compared to a biological ecosystem with a cyclical development, where the waste of some is used for the development of others, etc. [6]. The authors of such ecosystems, R. Frosch and N. Gallopoulos, envisioned production as an integrated, globally sustainable model of industrial activity. Along with this, M. Rothschild [7] defined the economy as an ecosystem, which, like ecological systems, is characterized by competition and exploitation, specialization and cooperation, learning and growth, where the strong, or rather the effective, survive, and the weak die. Later, at the end of the 20th century, J. Moore [8] introduced the term of "business ecosystem", interpreting it as a dynamically developing community, consisting of various actors creating and receiving new content in the process of both interaction and competition.

According to J. Moore, effective functioning requires awareness of the economic and social landscape and finding the effective partners in the field of innovation. Organizational leaders in this case begin to lead competitors and their business partners, creating new communities, whose members delegate to them the right to change the rules of competition and business conduct, thereby shaping future development.

At the beginning of the 21 st century, the theory of business ecosystems introduces the concepts of social and digital ecosystems, where a social ecosystem is understood as a set of interconnected enterprises and organizations consisting of consumers and suppliers, as well as economic, cultural and legal institutions, jointly developing and being influenced by the ecosystem [9], and digital - an environment in which software applications, services, knowledge, business models, training modules, etc. act as organisms, which interact, evolve, create combinations, turn into more complex species [10]. 
Later, M. Iansiti and R. Levien [12] include the term keystones in the use of business ecosystems, meaning key players, the number of which is insignificant, but the influence on the operation of the system is large, as opposed to niche players occupying a large share in the system. but have no influence.

Some authors compare ecosystems with technology platforms (TP), national technology initiatives (NTI) [13], as well as with regional innovation clusters as "a transitional form of business ecosystem in terms of the evolution of economic space" [13, 14], point to the network approach to organizing business ecosystems.

Such a wide variety of types and concepts of ecosystems in entrepreneurship and economics indicates the need for further study and generalization of the theoretical and methodological foundations of the formation and management of business ecosystems. "In the new world of advantage in the competition arise from knowledge of when and how to build ecosystems, from ability to operate ecosystems, providing their long growth and constant enhancement" - J. Moore wrote.

As G.B. Kleyner figuratively said, "the social and economic landscape" sprouts today ecosystems which in the short term will take in it the central place [15]. The members of such an ecosystem are individuals and organizations, defined as "living organisms", which include suppliers, customers, competitors, various information, consulting, marketing and financial companies that create the organization's marketing environment, i.e. almost all business stakeholders. In this context, an organization is considered not as a member of one industry, but as an element, an integral part of an ecosystem, which may include representatives of various sectors of the economy (which, in fact, is the fundamental difference), and the business environment in this case may be considered as overlapping business ecosystems. A new nature of competition arises when it is not individual companies and firms that begin to compete with each other, but business ecosystems. One of the goals of strategic partnerships is to support competitiveness in relevant activities.

The formation of partnerships is becoming one of the corporate development strategies of organizations, as the emphasis is shifted towards their external activities. Corporate social responsibility and responsible competitiveness are declared.

The study of the nature of the business ecosystem shows that the synergistic effect of the action of its elements is achieved as a result of the coordination of the activities of organizations of different functional orientation. To create new consumer value, joint efforts are required, first of all, of supplier companies, manufacturers and consumers, as well as other market agents, such as all kinds of consulting and marketing companies, research and training centers, etc. Thus, the development of the business ecosystem is considered today as a strategic partnership concerning the development of a common position and joint actions to form and meet needs. The independent activity of partners, their profile of activity is preserved, but a symbiosis of relations is being built.

Russian scientists look at the ecosystem model from three sides [13, 16]:

1. Ecosystem as a partnership of organizations involved in one way or another in the value chain (educational and research institutions, manufacturing and trade organizations, media, suppliers, customers, etc.).

2. Ecosystem as a self-developing organization - an organization as a "living organism" using innovative approaches to management.

3. Ecosystem as a platform (platform ecosystem) is a platform on which various companies participating in the ecosystem "live", offering various products and services and covering the widest possible range of client needs.

In this case, a platform is understood as a business that owns key tangible and intangible assets, helps ecosystem members find each other, allowing them to interact with each other and use each other's resources (for instance, to use a client base). Platform firms coordinate 
the activities of ecosystem member organizations by setting rules for interaction and resource use.

Among such platform ecosystems, there are transactional (providing transactions interaction) and innovative platforms that develop new products by a large number of developers. [16]. In turn, mobile ecosystems, university ecosystems, etc. are distinguished among innovation ecosystems. [17].

The formation of platform ecosystems has gone through several stages in its development. Initially, technological platforms were created as a tool for the development of an innovative infrastructure, which included government agencies, universities, business representatives, etc., which was understood as a communication platform for coordinating the efforts and interests of platform participants to form a strategic vision of the industry. In other words, it was about the organization of the production system of a certain product and the prospects for its development. [18, 19]. Then technological platforms were transformed, complement goods began to be produced not only by the company creating the basic category, but also by third-party firms on the basis of one platform. In the future, the concept of a basic manufacturing company went away, and the platform began to be viewed as a platform for interaction in production and distribution. Herewith, the platform firm does not create material products, its values are the resources of the participants and the policy that it implements to coordinate the interaction of ecosystem members [16].

While the platform as a whole provides opportunities for the exchange of certain values between independent groups, then the digital platform offers hardware and software for such an exchange. Naturally, in the digital economy era, it is more expedient and easier to work on digital platforms.

It should be noted that in the literature a lot of attention is paid to considering the essence and principles of the formation of platform ecosystems and much less to disclosing the content of an organization's ecosystem, considering a business participant as an independent living organism, which is a complex adaptive system, the development of which is often difficult to predict. Practitioners often talk about building an ecosystem around the core business, considering it as the main trend in the development of large companies.

\section{Systematization and interpretation of the principles of partnership in business ecosystems}

Partnership in business permeates all levels of inter-firm cooperation, but if earlier business partnerships were considered as separate contractual relations for the implementation of economic ties, the supply of raw materials, materials and finished products, or as scientific and technical ties and financial and credit relations, now all these the same connections should be defined as inter-firm team relations for the joint creation of customer value, ensuring co-evolution with the achievement of synergistic and emergent effects.

Unfortunately, in the literature, consideration of the fundamental foundations of partnership in business ecosystems is often unsystematic and fragmented. Thus, most authors distinguish complexity, self-organization, co-evolution and adaptation as the principles of construction and organization of such systems, which, pursuant to Yu.N. Androsika, synthesis of scientific directions: systems theory, synergetics and tectology [14].

The list of such principles seems to be deeper and broader. Considering partnership in the above context of business ecosystems, one should highlight its basic principles and features presented in Table 1, grouped into three main forms of relationships that arise in the course of activities within business ecosystems.

Let us consider in more detail the principles of relationships in business ecosystems presented in Table 1: 
1. The integrity of the system is ensured by the interconnection of its elements. Power and Gergian argue that as a member of a business ecosystem, one cannot run the business oneself, but one must manage the entire ecosystem [20].

2. Interdependence is driven by a shared focus on value creation with high coordination efficiency among interconnected ecosystem participants. The fundamental difference between business ecosystems and traditional schemes for creating customer value is the transition from its simple operational implementation to a systemic one, when the profitability of participants is increased due to synergy, which is achieved by simultaneously providing the client with a wide range of products and services in order to obtain additional benefits for them, while their use. Business ecosystems operate on the modularity principle, where the system consists of units, developed independently, but acting as a whole. [21]. In such conditions, the shortcomings of the work of one link may cause big problems for the entire system as a whole.

Table 1. Forms of relationships in business ecosystems and the principles on which they are built.

\begin{tabular}{|c|c|}
\hline Forms of relationship & Principles \\
\hline \multirow{4}{*}{ cooperation } & integrity \\
\cline { 2 - 2 } & interdependence \\
\cline { 2 - 3 } & complementarity \\
\cline { 2 - 2 } & mutual benefit \\
\cline { 2 - 2 } & self-organization \\
\cline { 2 - 2 } & transparency \\
\cline { 2 - 2 } & duplication \\
\hline \multirow{4}{*}{ competition } & confidence \\
\cline { 2 - 2 } & coexistence \\
\cline { 2 - 2 } & reaction \\
\cline { 2 - 2 } & adaptation \\
\hline \multirow{4}{*}{ symbiosis } & dynamism \\
\cline { 2 - 2 } & heterogeneity \\
\cline { 2 - 2 } & cross-cultural character \\
\cline { 2 - 2 } & self-learning ability \\
\cline { 2 - 2 } & coevolution \\
\hline
\end{tabular}

3. Complementarity determines the strategically different nature of the interaction of ecosystem elements (joint specialization). For example, Sberbank introduces medical services on its platform, including, in addition to online consultations, appointments to a doctor, online pharmacies, etc. a health diary with daily measurements of pressure, pulse, temperature or blood sugar level, which allows to save all measurement results in electronic form and make them available to the doctor, who will be able to notice critical changes faster than the patient senses and calls.

4. Mutual benefit. Partnership in ecosystems, as in traditional systems, is built on the principle of respecting each other's interests. Each of the entrepreneurial ecosystems is focused on optimizing the satisfaction of the interests of all its participants, otherwise the system becomes prone to decay or degeneration. [22].

5. Self-organization is the regulation of professional activities by the platform firm and by the participants of the business ecosystem themselves outside the framework of the requirements determined by the state in order to create the most favorable conditions for joint activities. Business ecosystems are the form where self-organization manifests itself most tangibly, since participants, as a rule, gather voluntarily and often without an external and internal leader. Objectives are determined through local action in the negotiation process and thus a new order is formed. In the process of evolution of business ecosystems, new 
connections are formed and old ones are disbanded. Thus, I.V. Boguslavsky and E.A. Ugnich, defining the concept of venture ecosystems, indicate that their goals are selfmaintenance and self-development at the expense of private capital of the interrelated elements of the venture business [23].

6. Business transparency (transparency) is one of the most important characteristics and conditions for the existence of a business ecosystem, its objective necessity, contributing to the individual competitiveness and competitiveness of the system as a whole, as it is associated with the observance of the principles of legal openness, with documentary reflection of the interaction of business with customers and employees, representatives government agencies, authorities, media, etc. The undoubted advantages of transparency are the presence of feedback and the intensification of joint activities. However, as studies carried out in this area show, despite the understanding of entrepreneurs declaring socially responsible business, the importance of business transparency, it is still possible to draw conclusions about the low level of its information transparency. [24].

7. Duplication of relationships. The sustainability of the development of the business ecosystem also largely depends on the possibility of replacing partners, which indicates the need for interchangeable suppliers, consumers of products, etc.

8. Confidence. As business partners, organizations must trust each other to achieve their goals. The key task of cooperation is always the formation of trust between the partners of the partnership, for the emergence and maintenance of which the openness of the participants, the creation of a network of knowledge and competencies, the acquisition of professional and organizational competence are required.

9. Coexistence is a type of relationship that assumes the peaceful existence of different systems, when, without abandoning competition, companies find separate general areas of cooperation. It is quite difficult to control the activities of the members of the business ecosystem in order to keep up with, not to fall out of it, it is easier to do this by working closely with them.

10. Reacting implies a response to what is happening among the participants of business ecosystems, since within multiactor systems knowledge spreads not only between competitors within one industry, but even between unrelated industries. Thus, business expansion is possible by obtaining new content in the process of both interaction and competition.

11. The adaptability of business ecosystems is in the very foundation of their formation. As J. Moore stated, "business ecosystems come from an initial whirlwind of the capital, the interest of clients and talent generated by a new innovation, the same as successful types arise from natural resources of sunlight, water and nutrients of the soil" [25]. Since the entire ecosystem is constantly adapting to external constraints, the complex infrastructure of interorganizational interaction within the business ecosystem necessitates the adaptation of the structure and functions of each participant in the system to constantly changing external conditions and insider integration processes.

12. The dynamism of development is characterized by an active search for new forms of interaction not only with all players in their business environment, but also outside it in neighboring industries.

13. Heterogeneity. The variety of forms of partners and types of activities within the business ecosystem contributes to the sustainability of its development. The sustainable state of ecosystems is the result of the fulfillment of two key conditions - the presence of elements (participants) of innovative ecosystems and their relationship with each other, which implies joint interaction and mutual consideration of the interests of each of the participants, as well as the diversity of ecosystem participants [18].

14. Cross-cultural cooperation. For successful interaction, it is very important to know the peculiarities of the corporate culture of partners and take them into account in the process 
of their activities. In the process of developing a business ecosystem, its common core values are formed, such as innovation - the ability to implement new methods of work, as well as the ability to see familiar phenomena from a new angle and discover hidden opportunities and implicit relationships that are shared by all members of the community.

15. Self-learning - producing new ways of thinking, constantly learning how to learn together, facilitating the learning of all agents in the system in the process of continuously transforming themselves, encouraging experimentation with new ideas and their dissemination. Developing themselves, the organizations develop the business partners as well. Hence the need for leaders to consider when making decisions their impact on members of the ecosystem and the entire ecosystem as a whole.

16. Co-evolution is a coordinated development policy for all agents of the business ecosystem. Entrepreneurial ecosystems have the ability to transform and change under the influence of the processes of exchange of information and energy both between the elements of the system and between them and the external environment. [22]. Companies that are part of the business ecosystem, in turn, should also be considered as independent ecosystems, i.e. growing and developing organisms, the evolution of which may cause a chain reaction of transformations within their community, give rise to its new properties that are not inherent in each of its members individually, which is called the emergence effect. This concept offers a fundamentally new approach to the interpretation of partnership as a resource that ensures the sustainable development of all members of the business ecosystem, their long-term life, as well as the development of the business ecosystem as a whole.

\section{Conclusions}

Building business partnerships within ecosystems is today a paradigm for business development, which will allow access to all resources of strategic partners, correctly distribute risks and increase their efficiency. The sustainability of the entire business ecosystem as a whole, as well as the sustainability of the development of its members, is largely determined by the existing partnerships, the basic principles of which are: integrity and interdependence, complementarity and mutual benefit, dynamism of development, adaptability, transparency, co-evolution, self-organization and self-learning, heterogeneity and duplication of relations, a corporate culture that declares and encourages innovation.

\section{References}

1. N. S. Ivashchenko, International scientific and technical symposium "Economic mechanisms and administrative technologies of development of the industry", 87 (2017)

2. Yu. S. Voynova, Scientific Papers of Free Economic Society of Russia, 93(1), 59 (2008)

3. T.V. Terentyeva, Ensuring stability of development of fishery enterprise structures during crisis (2011)

4. E.Yu. Pertseva, Russian magazine of project management, 2(2), 16 (2011)

5. Сбербанк, https://2017.report-sberbank.ru/

6. R. A. Frosch, N. E. Gallopoulos, Scientific American, 261, 144 (1989)

7. M. Rothschild, Bionomics: Economy as Ecosystem (1990)

8. J. F. Moore, The Death of Competition: Leadership \& Strategy in the Age of Business Ecosystems (1996) 
9. E. Mitleton-Kelly, Complex Systems and Evolutionary Perspectives on Organizations: The Application of Complexity Theory to Organizations, Ten Principles of Complexity and Enabling Infrastructures (2003)

10. F. Nachira, Towards a Network of Digital Business Ecosystems Fostering the Local Development (2002)

11. N. S. Ivashchenko, Design, technologies and innovations in the textile and light industry (INNOVATSII-2020), 3, 107 (2020)

12. M. Iansiti, R. Levien, The Keystone Advantage: What the New Dynamics of Business Ecosystems Mean for Strategy, Innovation, and Sustainability (2004)

13. V. D. Markova, I. S. Trapeznikov, World of economy and management, 16(4), 109 (2016)

14. Yu. N. Androsik, Papers of BGTU, Series 5: Economy and management, 7, 189 (2016)

15. G. B. Kleyner, SAinE - 2018, 5 (2018)

16. S. N. Konopatov, N. V. Saliyenko, NIU ITMO scientific j., 1 (2018)

17. S.V. Doroshenko, A. G. Shelomentsev, J. of the economic theory, 4, 212 (2017)

18. I. O. Volkova, A.Yu. Yakovleva, Innovations, 10(288), 52 (2018)

19. I. O. Volkova, E. D. Burda, Innovations, 5, 25 (2017)

20. T. Power, G. Jerjian, Ecosystem: Living the 12 principles of networked business (2001)

21. C.Y. Baldwin, K. B. Clark, Harvard Business Review, 75(5), 84 (1996)

22. Ye. L. Andreyeva, P. L. Glukhikh, Yu. G. Myslyakova, Manager, 9(6), 49 (2018)

23. I. V. Boguslavsky, E. A. Ugnich, Online magazine "NAUKOVEDENIYE", 2 (2014)

24. T. K. Golushko, O. N. Gorbunova, Social and economic phenomena and processes, 6 (2016) 